\title{
EL CH'ULEL EN LOS ALTOS DE CHIAPAS: \\ ESTADO DE LA CUESTIÓN
}

\author{
Elena Lunes Jiménez \\ 1_lunes@hotmail.com \\ Facultad de Ciencias Sociales \\ UNACH C-III \\ México
}

\section{RESUMEN}

El artículo presenta una revisión de la literatura generada alrededor de la noción y concepto de ch'ulel, basada en la cosmovisión tsotsil-tseltal, en el altiplano chiapaneco. De acuerdo con las interpretaciones que los autores han realizado sobre dicho concepto, la información se sistematiza sobre los siguientes significados: ch'ulel como alma; en la salud y en la enfermedad; en la conciencia de los niños; como control social; el vayijelal o animal compañero como vela de la vida y como calor. Se distingue el concepto de ch'ulel con ch'ulelal; este último vinculado con la celebración del día de muertos. Se expone en su conjunto y como aporte de este artículo el concepto de Mundo ch'ulel.

Palabras clave: ch'ulel, Mundo ch'ulel, persona, vayijelal.

\section{SUMMARY}

The article presents a review of literature generated around the notion and concept of ch'ulel, based on the Tsotsil-Tseltal cosmovision, in the high plains region of the state of Chiapas. According to the interpretations formulated by the authors on said concept, information is systematized on the following meanings: the ch'ulel as soul; in health and in sickness; in the conscience of children; as social control; the vayijelal or companion animal; as candle of life and as heat. The ch'ulel concept is distinguished from that of ch'ulelal, the latter associated with the celebration of the day of the dead. The concept of "ch'ulel world" is expounded as a whole and as contribution of this article.

Key words: ch'ulel, ch'ulel world, person, vayijelal. 


\section{INTRODUCCIÓN}

El presente artículo sistematiza los aportes de diversas investigaciones que han trabajado sobre el tema del ch'ulel, desde distintas perspectivas y lugares de estudio, incluyendo también a autores tsotsiles y tseltales. He realizado una revisión bibliográfica de personas que se han ocupado de reflexionar alrededor de la noción de ch'ulel en el altiplano chiapaneco. La exploración incluye autores que han trabajado este concepto en distintos periodos históricos, desde los años sesenta del pasado siglo hasta los primeros años del presente, intentando dar cuenta de los principales ejes que los trabajos revisados aportan en el debate del estudio del ch'ulel. A partir de este estudio, surge un concepto que he denominado Mundo ch'ulel, considerando este acercamiento como un concepto que nos permite tener una idea de la integralidad de los elementos, nociones, concepciones tangibles y no tangibles, los cuales conforman a la persona y a la sociedad, en su interrelación con el ch'ulel. Decido denominar de esta manera a lo que otros autores nombran como «lo otro de algo», el «mundo no visible», o lo comúnmente llamado «mundo sobrenatural».

El interés de analizar una noción como la del ch'ulel nace a partir de las distintas percepciones que se viven hoy en el municipio de Chamula dando como resultado la tesis titulada «Percepciones alrededor del Mundo ch'ulel en Chamula, Chiapas», que presenté para obtener el grado de licenciada en Antropología Social en el año 2008, bajo la dirección de la maestra Araceli Burguete Cal y Mayor. En donde, el «estado de la cuestión» forma parte del primer capítulo, obteniendo así un acercamiento al tema a desarrollar.

\section{ACERCAMIENTO CONCEPTUAL AL CH'ULEL}

El concepto ch'ulel ha sido de profundo interés durante varias décadas para distintos autores, ya que representa en la vida cosmogónica de los mayas tsotsiles y tseltales un rasgo cultural representado en el eje central de la percepción del mundo, siendo así una forma de describir su cosmovisión; es decir, la centralidad que el ch'ulel tiene en distintos aspectos de la vida, como en la salud-enfermedad y muerte; su relación con el poder, control social, género, parentesco y conflictos; así como su relevancia en el 
lenguaje e infancia, se representan en diversas prácticas y rituales de la vida cotidiana de éstos. Es una «cualidad» de explicar los sociales que los rodean.

Por ello, Mario Ruz menciona que «Todas las etnias mayences conciben la existencia de un componente —no físico- del hombre... Para algunas tal principio vital es unitario; para otras, fragmentado, pudiendo incluso hacerse extensivo a plantas, animales y objetos inanimados...» (Ruz 1992: 229). Es decir, no solamente la persona posee ch'ulel, sino todo aquello que se considera dentro del Mundo ch'ulel, esto es, que posea tanto la parte tangible — físico, material — como la intangible — sagrado, espiritual — y se le otorgue un valor sacralizado. Por ejemplo, al explicar el significado de las cruces en Zinacantán, Vogt menciona que estos objetos de características con valor poseen su propio ch'ulel: «El fenómeno del alma innata no es exclusivo del ser humano. En principio todo aquello que está "vivo", "animado", y que tiene valor para los zinacantecos, también la posee...» (Vogt 1992: 259).

El ch'ulel, traducido e interpretado como «alma» en lengua española, forma parte de la persona, por lo que el concepto «alma» le fue dado por los primeros investigadores para darle un sentido común, ya que «...ambos se originan en cosmovisiones muy diferentes ... dando como resultado una entidad, que por un lado es el soplo de Dios, reside y da sentido al cuerpo, y por otra, es una diversidad de seres etéreos y partes situadas dentro del cuerpo y en el espacio del Yan Vinajel-Yan Banamil - otro cielo-otra tierra-, con voluntad y emociones propias» (Page 2005: 177). Es por ello que surge la preocupación de presentar un estudio crítico a esta noción que diferentes autores denominan como alma, así señalo que el ch'ulel es descrito, traducido, significado y conceptualizado de esta manera, como «alma», desde su propia percepción, entendimiento y modo de ver; para entender y comprender este concepto dentro de la cosmovisión maya tsotsil-tseltal. Dando al mismo tiempo una propuesta conceptual que he denominado Mundo ch'ulel el cual engloba distintas características de la noción de «persona» vinculada con su entorno social, que se irá reconociendo a lo largo del texto.

Una primera aproximación al estudio del ch'ulel la da Pedro Pitarch, matizando el alcance de la traducción del tseltal de Cancuc al español, mismo que afirma: 
...el término «alma» es aquí una simple convención. La raíz de la palabra ch'ul- se traduce normalmente tanto de lengua tzeltal como tzotzil por «santo»o «sagrado». No obstante, para el desarrollo ulterior de mi argumento conviene reparar en que ch'ulel es «sagrado» solo en un sentido muy estricto, es decir, ch'ul es más bien lo «otro» de algo (Pitarch 1996: 32).

Dentro de esta precisión que hace el autor, de los conceptos alma y ch'ulel, refiere que existen ciertas características que los asemejan, pero ciertamente no son iguales. Asimismo, al traducir ch'ul como sagrado se pueden ejemplificar otros conceptos en donde el término ch'ul tiene la función de darle un sentido de sacralización a distintos elementos que son importantes dentro de la cosmovisión maya tsotsil-tseltal. Por ejemplo, iglesia se dice ch'ulna, que literalmente se traduce como «casa sagrada»; ch'ulme' — madre sagrada - quiere decir «luna»; ch'ultot — sagrado padre-, «sol»; ch'ulvits, «montaña sagrada»; ch'ulch 'en, «cueva sagrada»; ch'ulvo', «agua sagrada».

De esta manera se puede percibir que todos los elementos antes escritos y traducidos forman parte de la naturaleza y son considerados deidades o moradas de éstas dentro de la cosmovisión maya tsotsil-tseltal. Asimismo, este conjunto forma parte del Mundo ch'ulel, ya que siendo tangible representan la parte «no visible», ya que estos lugares y elementos son considerados sagrados.

Autores clásicos del tema, como Holland, traducen ch ulel como espíritu, definiéndolo como sigue: «la fuerza vital de la naturaleza, la energía dinámica, vivificante e indestructible, de todos los humanos, animales y plantas. En el hombre, el espíritu es el medio innato por el que expresa su carácter psicológico y social, la naturaleza esencial del ser humano» (Holland 1963: 99). A partir de esta definición, la fuerza, energía y carácter que el ch'ulel le da a la persona es sustancial, ya que a partir de la cosmovisión tsotsil, el ch'ulel tiene la capacidad de desprenderse del cuerpo, en situaciones de descuido, cuando la persona se encuentra dormida, en excitaciones fuertes — susto, orgasmo-; o cuando no puede retenerla - embriaguez-. Esta «ausencia de ch'ulel» en el cuerpo puede causar varios problemas que derivan en enfermedades, las cuales, si 
no se tiene especial cuidado, pueden llevar hasta la muerte, dependiendo de la fuerza que ésta posea. (Guiteras 1961: 229; Hermitte 1970: 55; Page op. cit., p. 169).

Dentro de las características del ch'ulel recogidas por los autores, se encuentra la división y alojamiento de éste en diversas partes del cuerpo. Al respecto, el ch'ulel se ubica en la garganta, generando el habla y, al mismo tiempo, en el corazón y/o la cabeza —mente—, procesando así el conocimiento (Hermitte op. cit., p. 110; Pitarch op. cit., p. 124). Del mismo modo, para Manuel Arias, informante de la antropóloga Calixta Guiteras en Chenalhó, el ch'ulel no solamente representa una unidad, sino que también dentro de ese mismo ch'ulel hay ramificaciones, pues «el ch'ulel es uno y múltiple» (Guiteras op. cit., p. 231). A esto, el número de ch'ulel en la persona puede variar, siendo trece la cantidad «perfecta», ya que es un «número importante en su cosmología y sistema calendárico» (Vogt op. cit., p. 258). Es decir, una persona puede poseer trece ch'ulel, caracterizándose como una«persona completa», con estatus determinado, sabiduría más amplia, poder y control sobre los demás (Pitarch op. cit., p. 72; Hermitte op. cit., p. 96; Page op. cit., p. 173).

Para comprender los rituales, las actividades religiosas, el calendario, relacionados con el número trece, se asocia a la cosmovisión del maya, en el que la tierra es el centro del universo. «Para los tzotziles y otros pueblos de América, la tierra es el centro del universo ... teniendo una superficie plana pero sin perder la visión de un espacio con ordenamiento piramidal de trece escalones hacia arriba y nueve hacia abajo o mundo inferior, Olontik, Xib 'alb'a, mundo de los muertos» (Saq Ch'umil 2003: 19-20). A esta noción del mundo y del universo, con el tiempo y el espacio, se relaciona con el cuerpo humano, explicando de esta manera a la persona completa de trece ch'ulel. «En el cuerpo humano se localiza además, trece puntos energéticos y trece puntos propiciadores del movimiento corporal... Este número está relacionado con la perfección y cúspide piramidal de plena realización o supramundo y con el resplandor de las trece constelaciones, llamadas también cielos o soles" (ibíd., p. 27). Observamos, entonces, la importancia de esta posesión de trece ch'ulel o tece vayijelal, como veremos más adelante. 
En las últimas décadas, en Chiapas se han formado investigadores, escritores e intelectuales mayas, tsotsiles y tzeltales principalmente, que se han preocupado por trascender en este ámbito antropológico, en el que por distintas causas institucionales han afrontado temas de su propio lugar de origen, como etnografías, relatos de cuentos, leyendas, escritos en español y en bats'i k'op, «lengua verdadera». Y si bien al hablar en su propio idioma la noción de ch'ulel tiene connotaciones de sacralización propias de la cosmogonía maya; sin embargo, a la hora de publicar en español, muchas veces se ven obligados a realizar traducciones que ya son una suerte de convención en su uso. Tal es el caso de traducir ch'ulel como «alma». Traslación que se ha naturalizado y que ya no es vista críticamente, impidiendo interrogarnos sobre la conveniencia de las traducciones de conceptos tan complejos en la cosmogonía maya. A esto, Vogt recalca que conceptos como alma y espíritu es importante definirlos desde la cosmovisión maya, ya que «es inadecuado utilizar estas palabras porque evocan los conceptos europeos...» (Vogt 1966: 115).

Siendo el ch'ulel un concepto polisémico estudiado y en consecuencia definido de manera diversa, se pueden obtener diversos significados equivalentes al significado propio de los tsotsiles. Miguel Sánchez (2006: 56) —escritor tsotsil, define ch'ulel como «conciencia», dándole un nuevo significado. Por ello, el concepto de ch'ulel es representado no solamente como un elemento anímico considerado así en varios estudios bibliográficos, sino como un concepto en donde lo sociocultural interviene.

Por su parte el escritor tsotsil, originario de Chenalhó, Jacinto Arias, en su texto El mundo numinoso de los mayas, menciona que el ch'ulel es parte del mundo numinoso o parte del Mundo ch'ulel, es decir, la «...parte de lo invisible, de lo mágico, de lo sobrenatural, de lo divino, de lo sagrado. Surge en la mente a partir de experiencias individuales y comunales; asimismo está cargado de moralidad y racionalidad» (Arias 1975: 15). En ese esfuerzo analítico, el autor divide la concepción del mundo en dos: lo visible y lo no visible. En el mundo visible se encuentra todo lo que somos y lo que nos rodea; y lo invisible es lo que - las personas «normales»- no podemos ver. Es «la parte "alma" del mundo visible» (ibíd., p. 39), donde los j'iloletik, curanderos, son los únicos que pueden ver la parte visible y la parte invisible, el otro cielo-la otra tierra. 
Desde esta interpretación, ch'ulel como parte sacralizada de la persona, el cuerpo es su morada temporal, la cual hay que educar para atraerlo, ya que de lo contrario «si no está bien habituada, la persona enfermará, pues abandonará el cuerpo muy fácilmente» (ibíd, p. 40). Entonces, también el ch'ulel representa el buen comportamiento social formado desde la educación.

\section{LLEGADA DEL CH'ULEL Y FORMACIÓN DE LA PERSONA}

Dentro del ciclo de vida de los mayas, el ch'ulel se empieza a manifestar desde el embarazo, en el momento en que el embrión se empieza a agitar dentro del vientre materno (Guiteras op. cit., p. 95; Hermitte, op. cit., p. 54; Page op. cit., p. 172). A esto Miguel Hernández, en su estudio sobre las ideas y creencias en los mitos de Larráinzar, menciona cómo los totil me'iletik, padres-madres, hacen llegar el ch'ulel a cada persona: «El ch'ulel [alma] es colocado por los totil me'iletik en el embrión y, se cree, es de la mayor importancia para la salud en la vida de la persona; por ello, el ch'ulel es una especie de animal conservado por los totil me’iletik...» (Hernández 1997: 73). En esta cita se menciona a un «animal», animal compañero o vayijelal, que más adelante se expondrá y que también forma parte de este Mundo ch'ulel. De igual forma es considerada la descripción de la llegada del ch'ulel por los zinacantecos, pues «El ch'ulel es colocado por los totilme 'iletik en el embrión...»(Vogt 1966: 115).

Durante este proceso, a veces el ch'ulel escapa del feto. Según Guiteras, «El ansia de escapar se debe al hecho de que el alma del infante puede haber vivido en la tierra con anterioridad en lugares alejados. Asimismo puede aprovecharse de la oscuridad para huir, pero cuando al dar a luz una criatura muerta indica que el alma ha estado demasiado intranquila» (Guiteras op. cit., pp. 95-96). En este primera etapa —durante y después del embarazo - debe haber un cuidado especial tanto en la madre como en el niño, por la delicadeza en la inmadurez que tiene su ch'ulel. A esto Hermitte menciona: «hasta los cuarenta días los niños son todavía muy tiernos y susceptibles de perder su espíritu ... Si un niño nace con muy buen espíritu y los me’iltatiles lo saben, pueden robárselo para ponerlo en sus propios hijos (Hermitte op. cit., p. 55). 
En los estudios realizados por Lourdes de León, el ch'ulel se va adquiriendo a través de la «socialización por el lenguaje», es decir, se basa en la adquisición del lenguaje durante la infancia, definiéndolo como «la llegada del alma», donde tener ch'ulel es un conjunto total de capacidades que se van estableciendo socialmente: «Tener ch'ulel representa un tejido de fibras de naturaleza lingüística, emocional, cognitiva y cultural» (De León 2005: 324). Mediante el lenguaje, según esta autora, se expresan el entendimiento, las emociones y los sentimientos del niño. Tener ch'ulel en Zinacantán representa la manera correcta de «ser persona», que significa «tener razón», es un proceso en el cual el ch'ulel se va desarrollando. «La expresión ta xtal xa xch’ulel, "ya viene el alma", se refiere al proceso por el que atraviesa un infante para convertirse en "persona", proceso que implica la capacidad gradual de atender, entender, comunicar, participar y actuar de manera zinacanteca» (ibíd, p. 25). Es decir, el niño se va desenvolviendo y va adquiriendo las características culturales de la sociedad en la que convive. Asimismo, el término que maneja De León, recuperado de los zinacantecos, oy xa xch'ulel, es un discurso real que engloba características donde el niño se define como ser persona.

El proceso de la llegada del ch'ulel, desde el estudio de esta autora, se manifiesta en tres etapas: La primera, «ch'abal to xch'ulel: “todavía no tiene alma, entendimiento"... Le sigue, ta xtal xa xch'ulel: "ya viene el alma, el entendimiento" .... Y la tercera, oy xa xch'ulel: "ya tiene alma, entendimiento"...» (ibíd., p. 58). Después de este proceso, al paso de los años el término «ya tiene alma» cambia y deja de ser utilizado, pues una persona que ha pasado por estas etapas se dice que ya posee ch'ulel. Ello se puede comprender mejor a partir de las prácticas que vayan realizando los niños, que se da «después de los cuatro años, reemplazado por comentarios relacionados con las capacidades de trabajo de los varones — kerem - Entre los cinco y los siete años se comenta de las niñas — tzeb— si ya saben hacer tortillas» (ibíd., p. 59).

El trabajo reciente de Lourdes de León nos hace dar cuenta de cómo el ch'ulel ha sido objeto de estudio sicológico y lingüístico, abarcando otras áreas que ayudan a explicar no solo prácticas rituales de los tsotsiles, sino también a comprender mejor el comportamiento de los infantes durante el proceso de su formación. 


\section{FORMACIÓN DE LA PERSONA}

Sobre la adquisición del conocimiento en relación con el ch'ulel, Pitarch enuncia que «el ch'ulel junto con los otros dos tipos de "almas" - ave de corazón y lab - nace junto con el individuo, y es la mente la que viene vacía y por medio del aprendizaje se va rellenando de conocimientos, a través de los sentidos, por medio del aprendizaje y la experiencia cultural» (Pitarch op. cit., p. 124). Así, los conocimientos se van codificando a partir de la razón social, siendo la experiencia a través de los años la que ayuda a la persona a adquirirlos.

A esto, Manuel Arias menciona que «Las emociones, los impulsos, los deseos, los apetitos, surgen del corazón, mientras que el conocimiento del bien y del mal se encuentra en la mente» (en Guiteras op. cit., p. 235). Siguiendo esta relación entre corazón y mente — cabeza—, se puede explicar el lenguaje, ya que «las palabras brotan del interior del corazón, cuando se habla las palabras deben pasar por la cabeza y son elaboradas en la boca» (Pitarch op. cit., p. 124). Observamos, entonces, esta similitud de la adquisición del lenguaje con lo antes mencionado por De León.

\section{EL CH'ULEL EN LA SALUD, MUERTE Y ENFERMEDAD}

Dentro de la cosmovisión maya, y siendo parte del Mundo ch'ulel, la enfermedad y la muerte son consideradas como un mal causado por terceras personas y/o deidades, por lo que no es pensada como natural, las cuales pueden ser provocadas por envidia, coraje o simplemente por el gusto de hacer daño a la gente. Existen varios tipos de enfermedades, mismas que se encuentran relacionadas con el ch'ulel, a veces se pueden visualizar en los sueños.

Helios Figuerola (1996), en su análisis de estudio sobre una oración para buscar el ch'ulel en San Juan Cancuc, menciona que las enfermedades se pueden distinguir en «naturales»y «sobrenaturales», las segundas son «provocadas por un hechizo, cuya exégesis es la consecuencia del ataque del lab de un brujo [ajchamel] al ch'ujlel de la víctima para tratar de devorarlo», también, «aparecen como la respuesta a una transgresión al orden social...». A partir de esta concepción de las enfermedades 
denominadas «sobrenaturales», es necesario para poder contrarrestarlas un ritual de curación efectuado por un j'ilol —curandero.

La definición que Köhler hace de las enfermedades, relacionando éstas con el ch'ulel, son denominadas ch'ulelal. «Todas las dolencias que tienen su causa en el ámbito de las almas, de los animales compañeros o de los holomal [nagual o lab, para los tseltales], se denominan č'ulelal [ch'ulelal] ... Ch'ulelal es la forma abstracta de ch'ulel, "alma"; aquí con el significado de "lo que toca el alma", "problema del alma", "enfermedad del alma”» (Köhler 1995: 22-23).

A esto, Page menciona que «el ch'ulel es un elemento importante de la persona como en la adquisición de enfermedades al ser descuidado por su dueño, ya que la vida depende de éste, su ausencia del cuerpo y de las otras entidades anímicas, primero debilita y finalmente mata» (Page op. cit., p. 168). Según este autor, para que el ch'ulel no salga del cuerpo y se encuentre resguardado por las deidades se necesita darles ofrendas. Es decir, la debilidad de un ch'ulel se origina principalmente por no ofrendar a Dios y, en consecuencia, «los Anjeletic y los Apóstoles no se preocupan por cuidarlo ni por sostenerlo» (ibíd., p. 173). Según Page, la principal causa de las enfermedades en relación con el ch'ulel es el descuido por parte de las mismas personas, por ejemplo, al omitir los sueños donde se dan avisos de futuras enfermedades, ya que «Una persona puede soñar "cosas" que hacen dar cuenta de que su ch'ulel está corriendo algún peligro...» (ibíd., p. 174).

Entre las enfermedades más comunes relacionadas con el ch'ulel, se encuentra el xi'el — susto-, el muk'ta ch'ulelal —atrapado el alma—, el mal de ojo, el robo y venta del ch'ulel, la captación de k'al o «cortar hora», esto relacionado con la «vela de la vida» —que se explica más adelante-. En cuanto al xi'el, susto, según Page es generado por terceros sujetos, por deidades; y la gravedad va a depender del lugar donde hayan ocurrido los hechos, por ejemplo en el camino, ojo de agua, cerca del río o cerca de las cuevas. «Si el ch'ulel es atrapado por algún Anjel rojo o negro, o por otro ayudante del enemigo, permanecerá en el lugar donde la persona se asustó» (Page op. cit., p. 242). 
Esta enfermedad se manifiesta comúnmente en los niños, en quienes su ch 'ulel todavía no se ha fortalecido.

En cuanto a la curación de las enfermedades, es necesario diagnosticar el origen de ésta, mediante la toma del pulso es un método que se utiliza para llevar a cabo el ritual de curación. Se cree que a través del pulso se puede hablar con el ch'ulel, así los j’iloletik — curanderos - son los que tienen la capacidad de platicar o escuchar al ch'ulel de la persona afectada. Holland menciona esta «plática» que hay entre el curandero y el ch'ulel, citando a Villa Rojas, quien explica el papel importante que juega el pulso para remediar las enfermedades. «El curandero "habla con el espíritu” tomando el pulso, e intenta adivinar la situación del animal compañero, así como la naturaleza de la enfermedad» (Holland op. cit,p. 184).

La enfermedad se puede considerar también como un tipo de sistema de «control social», ya que es lanzada principalmente como castigo por parte de los curanderos hacia los «pecadores» y/o a los ofensores, pues ellos son los guardianes de la tradición y de las normas morales. «Tener conciencia de los actos que violan las normas de la tradición y pedir perdón por ellos es el primer paso en las prácticas terapéuticas. Ser jactancioso ante la gente, especialmente ante las personas con experiencia, provoca la ira y los celos, tarde o temprano es causa de infortunio, especialmente en forma de enfermedad» (Arias op. cit., pp. 41-42). Por su parte, Magdalena Gómez Sántiz, quien hace un estudio sobre los médicos tradicionalistas en distintos municipios de Los Altos de Chiapas, menciona que «los tsotsiles consideran que la enfermedad es un desequilibrio, falla o deterioro de algún órgano del cuerpo humano, este tiene como componentes no corpóreos el ch'ulel —espíritu inmortal- y el vayijel —animal, compañero mortal (Gómez 2005: 56).

Asimismo, Miguel Hernández menciona que «Mientras tanto los hombres deben cumplir con el respeto a sus semejantes y a las cosas, con el fin de evitar el desprecio de su ch'ulel por los totil me'iletik ... ellos pueden dejar fuera del corral a su ch'ulel si desobedece órdenes establecidas por el totil me'iletik, con lo que correrá riesgo de muerte» (Hernández, op. cit., p. 73). Lo anterior explica el ch'ulel como control social, 
pues el respeto es una característica fundamental dentro de la cosmovisión maya, ya que en ello se da la estabilidad y fortaleza de estos pueblos.

En el estudio que hace Hermitte, en Pinola — actualmente Villa Las Rosas-, explica acerca del poder «sobrenatural» como control social. Este poder «sobrenatural» se caracteriza en ciertos agentes sociales, que la misma sociedad les otorga, entonces adquieren «autoridad» ante los demás, obteniendo un estatus con el poder de castigar, vigilar, curar. Esta autoridad se adquiere ya sea por medio de cargos políticos y/o religiosos, además de por los conocimientos que vaya acumulando en las experiencias de la vida. Según este estudio hay tres tipos de agentes de control social: me 'iltatil que cuidan a los individuos y a la comunidad-, poshtawaneh - a cargo de la curación de enfermedades—, y los ak'chamel — dedicados a «echar mal»—, siendo estos los tres roles más importantes en el control social de esta comunidad» (Hermitte op. cit., p. 155). Existe también otro tipo de personas que vigilan a la gente, aunque las decisiones que toman son dadas por sus ch'uleltik en una reunión. Es decir, «estos se reúnen en cierto lugar a un nivel sobrenatural, cuando se reúnen en "sus espíritus" y deciden sobre lo que debe hacerse respecto de los trasgresores» (ibíd., p. 158).

Todos estos agentes forman al mismo tiempo un «gobierno sobrenatural». Es decir, en este «mundo» —el cual se podría denominar Mundo ch'ulel — también existen rangos, cargos, estatus. «Los pinoltecos los nombran presidente, secretarios, juez, etc., es la manera de cómo ellos mismos clasifican a estos agentes, castigadores o cuidadores. Pero nadie sabe quiénes son (ibíd., p. 159).

Asimismo, Holland explica que «las enfermedades son interpretadas como un castigo de las fuerzas sobrenaturales aplicado al que trasgreda las pautas tradicionales de la sociedad ... la enfermedad es, entonces, el resultado lógico del desacuerdo entre un individuo y su sociedad, que da lugar a las sanciones mágico-religiosas por su comportamiento» (Holland op. cit., p. 120). 
Percibimos hasta ahora cómo la noción de «respeto», tanto a las normas morales sociales como a las deidades, es importante. Por eso, en el trabajo realizado por Jane Collier sobre los conflictos y su resolución a través del ch'ulel, define «las almas» - ch'ulel, vayijel - para entender la situación de brujería ${ }^{1}$ como causa principal de enfermedad. Así, menciona que las enfermedades del cuerpo humano provienen principalmente por dos situaciones relacionadas con su ch'ulel. Una es la brujería, provocada por ch'uleltik más fuertes; la segunda relacionada con su envío por las deidades como castigo ordenado o pedido por las mismas personas. Según Collier, «estos problemas se originan desde este otro mundo, en donde los ch'uleltik son los que se pelean y en consecuencia son las personas las que sufren estos daños por los conflictos que surgen en la sociedad» (Collier 1995: 135).

\section{DESTINO DEL CH'ULEL EN LA MUERTE DE LA PERSONA}

En la cosmovisión maya la muerte, al igual que las enfermedades, no es por causas naturales, «ya que se cree que es un mal lanzado por el hombre contra sus semejantes, o de un golpe de los dioses. En ambos casos, el vayijelal ha sido "devorado"» (Guiteras op. cit., p. 124). Asimismo, la concepción acerca del destino del ch'ulel después de la muerte se asemeja en diversos estudios realizados alrededor del tema. Entre algunas de estas percepciones, el ch'ulel después de la muerte se va al vinajel, cielo, o al k'atinbak, infierno, dependiendo de la manera de «como hayan muerto» (Guiteras op. cit., p. 127), no de qué manera hayan vivido sobre la tierra.

Jane Collier conceptualiza al destino del ch'ulel para determinar que el castigo no es eterno, pues «el ch'ulel, después de la muerte, solo existirá la misma cantidad de tiempo que la persona vivió aquí en la tierra. Entonces el castigo que sufrirá su ch'ulel y la persona es en un determinado tiempo» (Collier op. cit., p. 147). En este sentido, Page sitúa al ch'ulel en un estado en el que no ha pertenecido a alguna persona, es decir, el ch'ulel llega a ser hasta cierto punto nada. «No deja de existir, sino pierde la noción de que pertenece o debe pertenecer a un ser humano (Page op. cit., p. 175). 
En la cosmovisión de los chamulas, estudiada por Gossen, el mundo se divide principalmente en tres partes: el cielo, la tierra, el infierno — según lo denomina el autor-. Según este estudio, el infierno es donde habitan los muertos, al mismo tiempo se describe como la parte «pilar» del universo.

...la vida en el submundo es muy parecida en general a la vida en la tierra. Allí las personas no sufren, con la sola excepción de las que han matado a alguien o cometido suicidio. A éstas el sol las quema cuando recorre su circuito por el mundo subterráneo durante la noche de la tierra. El mundo subterráneo es también el punto desde el cual se sostiene el universo (Gossen 1980: 43).

En relación con este lugar como destino de los ch'ulelaletik ${ }^{2}$, Enrique Pérez - escritor tsotsil - menciona que al morir una persona «el espíritu ha emprendido el viaje al lugar eterno, ya sea el cielo o al k'atinbak -infierno-, que son los lugares donde van las almas de los difuntos» (Pérez 1997: 97). A esto, Ruz refiere «la suerte que corren los diversos tipos de "espíritus" tras la muerte del cuerpo, que aunque parece estar muy difundida la dicotomía cielo-infierno, el grado de asimilación de estos conceptos judeocristianos se muestra en extremo variable, pudiendo observarse elementos de clara raíz prehispánica en casi todas las etnias» (Ruz op. cit., p. 230). Percibimos entonces que conceptos como $k^{\prime}$ atinbak se dan por las semejanzas que las interrelacionan. Al respecto, dentro de la cosmología estudiada por Holland, se define olontik - del término tsotsil «olon: abajo»—, como el mundo de los muertos, el cual se ubica debajo de la tierra y se encuentra «constituido por nueve, trece, o un número indeterminado de escalones (Holland op. cit., p. 69).

Es importante señalar la relación y la concepción que se tiene acerca de la sombra con el ch'ulel, pues según Pitarch menciona que la sombra es una manifestación de que el ch'ulel está en la persona.

Noketal es la sombra del cuerpo en condiciones de sol, luna y otra fuente de luz, pero parece que ésta no es tanto una proyección del cuerpo como del ch'ulel alojado en el interior del corazón. Ello explica la convicción de que un cadáver, cuando va ser inhumado, carece de sombra, puesto que ésta desaparece en el preciso instante en que el ch'ulel abandona definitivamente el cuerpo (Pitarch op. cit., p. 52). 


\section{RELACIÓN DEL CH'ULEL CON EL COMPONENTE ANÍMICO K'AK'AL - CALOR- Y VELA DE LA VIDA}

He considerado parte del Mundo ch'ulel al componente k'ak'al, k'al -calor, temperamento, fuerza, día, energía - por su significado dentro de la concepción de persona, pues ésta forma parte de aquel y se relaciona de manera importante con el ch'ulel. En la investigación que realiza Henri Favre afirma que, lo que comúnmente se le llama ch'ulel no es lo que se piensa hasta ahora, o sea, no es el alma en un concepto cristiano, sino ch'ulel se le ha llamado a un concepto que en la cosmología de la persona maya se conoce como $k^{\prime}$ al, «Esta fracción individual — pero no personalizada- de $k$ 'al, que todo hombre posee y se esfuerza por aumentar, se llama ch'ulel» (Favre 1992: 258).

Al respecto, Jaime Page menciona que este elemento representa el «lazo sobrenatural que mantiene unido el cuerpo con sus entidades anímicas y a éstas entre sí. Aquellas partes que han formado parte del cuerpo o estado en contacto con éste por mucho tiempo — pelo, uñas, orina, excremento, dientes, ropa, ch'ulel, vayijel, quibal...» (Page op. cit., p. 164).

Por su parte, para Manuel Arias el calor es otra característica del ser humano, la cual lo relaciona con los dioses o seres poderosos que conservan y destruyen la vida; por medio del calor el hombre se asemeja a Dios. Es asociado con la virilidad, la edad y el desempeño de una función gubernamental, en su relación con el ch'ulel, «Se dice que un hombre tiene, desde su nacimiento, más calor que una mujer; que su ch'ulel es más fuerte que el de aquélla» (en Guiteras op. cit., p. 237).

De igual forma, Gossen relaciona el calor con el ciclo de vida. La persona al nacer posee poco calor y mediante su crecimiento físico y social lo va fortaleciendo.

El bebé tiene un aspecto peligrosamente frío ... El niño adquiere un calor en constante aumento con el bautismo y la madurez sexual. El calor del ciclo vital alcanza un elevado nivel con la madurez social, que se expresa mediante el casamiento y la reproducción. Todavía se puede adquirir más calor, ocupando un cargo o mediante la carrera shamanista (Gossen op. cit,. p. 60). 
A lo largo de la vida una persona, tsotsil o tseltal, va desarrollando sus diferentes elementos, entre ellos el aumento de $k^{\prime}$ al, por lo tanto los moletik — ancianos- tienen la característica de acumulación de conocimientos, manifestándose en el respeto y autoridad que poseen ante los demás, pues ellos son los que «ven al mundo de manera más clara ... su persona no le pertenece a él, sino al grupo de ascendencia común, de la que es representante en la comunidad de los vivos, los muertos y los espíritus» (Favre op. cit., pp. 262-263).

En los moletik se presume que esta etapa las ansias de poseer mayor cantidad de $k^{\prime} a l$ aumenta, por lo tanto representa peligro ante los de menor cantidad, que es el caso de los niños. Así, Favre menciona: «En efecto, al encaminarse hacia la vejez, el hombre aumenta su fracción individual de $k^{\prime} a l$, pero la esencia vital solo existe en cantidad limitada en la naturaleza y, por ello, solo puede aumentarse la fracción individual de $k^{\prime} a l$ en detrimento de otro ... quien es más viejo que los otros tiene que haber robado el k'al de sus allegados» (Favre op. cit., p. 264). A ello, Hermitte añade que «Si un niño nace con muy buen espíritu y los me'iltatiles lo saben, pueden robárselo para ponerlo en sus propios hijos» (Hermitte op. cit., p. 55). Un ejemplo de esto es lo ocurrido con una anciana tsotsil a quien la roban el «don» de ser curandera a partir de un sueño en el que su madrastra le quita una canasta de frutas, significando para ella esta aptitud especial.

La importancia del calor en la cosmovisión tsotsil se manifiesta de igual forma en los rituales como las oraciones, pues el que sabe rezar significa que posee buena cantidad de calor. «Se afirma que el estilo poético repetitivo en oraciones, cánticos o fórmulas rituales refleja el "calor del corazón”. De manera similar, el tabaco, el ron, el incienso, las velas y los fuegos artificiales, generan o emiten calor» (Gossen op. cit., p. 61). A partir de esta afirmación, los que ya no practican rituales donde intervienen elementos como el pox, las oraciones, las velas, el incienso, por ejemplo los que cambian de religión, ya no emiten este calor conceptualizado como k'al. Este mismo autor relaciona los rituales chamulas con la deidad del sol, pues este símbolo representa en el pensamiento chamula algo como el «otorgador y conservador del orden. Ningún ritual chamula deja de hacer innumerables referencias, en lenguaje y acción, a esquemas 
cuyo origen proviene del momento cosmogónico en que el sol ascendió a los cielos» (ibíd., p. 69).

Cabe mencionar que dentro de los conceptos relacionados y encontrados en la literatura respecto al tema del ch'ulel, y dentro del Mundo ch'ulel, ubicamos a «la vela de la vida», la cual es determinada como la «medida» con la que se va consumiendo poco a poco la vida física de cada persona, se suma que está al cuidado de un ser superior. La representación de esta vela, precisamente se simboliza con las velas utilizadas en los rezos, por ejemplo, lo que representa la vida es una vela multicolor, a lo que le nombran como «oro».

Existe un ritual denominado kuxlejal, que literalmente significa «la vida», mismo que es una ceremonia de alargamiento de vida, también llamado orail, que significa «tiempo», y no es una adaptación o préstamo del español, si no coincidencia con la palabra «hora». Entre los tsotsiles se cree que la vela es plantada en el momento del nacimiento y depende de la persona cómo la quiera ir gastando, donde el rezo sigue siendo parte importante para el alargamiento de la vida. Este ritual es para que la vela no se apague y se vaya consumiendo lentamente de una manera homogénea, así también para que no sea objeto de enfermedad. «Los chamulas denominaron la vela de la vida «entorno», a la cual año con año se realiza un complejo ritual personal y familiar para alargar la existencia, y a la que en ningún momento se dio la connotación de entidad anímica» (Page op. cit., p. 161). Ello explica la cantidad de velas en un ritual de curación en relación con el número de integrantes de una familia.

En el municipio de San Andrés Larráinzar, el dueño y cuidador de las velas es el santo patrono San Andrés, ya que él «tiene tantas velas blancas como habitantes el municipio; estas velas representan sus vidas. A medida que la vela se gasta, el individuo va viviendo, hasta que, al extinguirse la vela, muere» (Holland op. cit., p. 80). Al respecto, Pitarch menciona que las velas de la vida se encuentran «Sobre una plataforma rectangular que se halla arriba, en el aire ... hay colocadas un sin número de velas blancas que corresponden a las vidas de todos los hombres del mundo, indígenas o no. 
Las velas, según algunos, están al cuidado de un enigmático jtatik velarol ["nuestro padre velador"]». (Pitarch op. cit., p. 82).

Los zinacantecos a este elemento lo llaman suerte $u$ «ora», la cual es manipulada para enfermar a la persona. «Esta suerte es representada como una vela encendida, y un jtuk' kantela [brujo "cortador de velas"], jtuk' ora [“cortador de suerte"] rebana las velas en pequeños pedazos, cortando la vida de la víctima y dejándola expuesta al ataque de una enfermedad fatal (Collier op. cit., p. 142).

\section{VAYIJELAL. EL ANIMAL COMPAÑERO}

La concepción de persona o naturaleza humana desde la cosmovisión maya se encuentra conformada por elementos como el ch'ulel, el vayijelal o chanul — animal compañero, el k'ak'al —calor - y el cuerpo, la sustancia física (Page op. cit., p. 160; Favre op. cit. p, 257; Holland op. cit., p. 99; Collier op. cit., p. 136; Pitarch op. cit, p. 32; Guiteras op. cit., p. 229; Vogt 1966: 115). Todo ello incluido en el concepto Mundo ch'ulel, porque son elementos «no visibles» que conforman a la persona, y que están en la concepción de ella. De esta manera, la «noción de persona tsotsil» como eje central del campo de investigación de Jaime Page para su estudio sobre medicina maya, es una «multiplicidad de cuerpos, animales y almas de los cuales la mayoría se moviliza preferentemente durante la noche, entidades que acceden a la conciencia de las personas principalmente a través de los sueños» (Page op. cit., p. 160).

Es por ello que dentro de los estudios realizados para describir a la naturaleza humana el vayijelal — animal compañero- aparece como un segundo «espíritu», «alma» o «ser» - traducido así por los autores-, de la persona, haciéndose de éste un concepto complejo, ya que al mismo tiempo de ser «no visible» es físico, pues es representado por un animal que existe físicamente y habita en cierto tipo de montañas, conformando igualmente al Mundo ch'ulel. Asimismo, demuestra la relación existente entre los seres humanos y la naturaleza (Guiteras op. cit., p. 229; Holland op. cit., p. 100). 
Es preciso señalar la diferencia del vayijelal con el nagual y el tonal. Mercedes de la Garza señala: «...por una confusión de los términos iniciada seguramente por los frailes y cronistas coloniales, quienes no lograron entender la diferencia ni el sentido de estas creencias en torno a los vínculos con los animales, resulta que a veces hasta los propios indígenas llegaron a llamar nagual al compañero animal»(De la Garza 1990: 173). De igual manera explica al animal compañero como el alter ego animal de cada persona, llamado éste «tonalismo», y su diferenciación con el nagualismo.

...un alter ego animal en el que habita una parte del espíritu de cada ser humano, por lo que el hombre está ligado a su animal desde el momento de su nacimiento hasta el de su muerte, compartiendo con él su destino. A este concepto se le ha llamado tonalismo ... mientras que transformarse a voluntad en animal es un poder sobrehumano que sólo unos cuantos llegan a poseer: los naguales (ibíd., pp. 172-173).

En el estudio que lleva a cabo Miguel Hernández, este traduce al nagual como ch'ulel chon, mencionando que «En la región batz’i viniketik se reconocen como naguales [ch'ulel chon], son animales grandes que se convierte en ch'ulel o chanul para proteger las almas de las personas» (Hernández op. cit., p. 72). Al mismo tiempo, este animal compañero le da ciertas características físicas y espirituales a la persona, ya que le «aporta la fuerza espiritual..., la inteligencia y la fuerza para el trabajo pesado. De tal forma que el animal moldea con vigor el cuerpo y hermosea el espíritu» (ibíd., p. 73).

De esta manera, Pitarch explica el lab — nagual, traducido en lengua tzeltal- que no son solamente animales y/o seres celestes, sino también herramientas, y hasta de cierto tipo de personas, «Estos últimos son los llamados ak'chamel "dadores de enfermedad"»" (Pitarch op. cit., p. 63). A diferencia de los tsotsiles de Larráinzar, estudiado por Holland, el animal compañero será dependiendo de lo que crean los demás. «Va ir cambiando a partir de que la persona vaya cambiando de estatus a lo largo de su vida. ... tanto el animal como el hombre maduran, y mientras esto sucede, ambos alcanzan una mayor fuerza, sabiduría e importancia» (Holland op. cit., pp. 103, 104). 
El número trece en el vayijelal también posee importancia. Al respecto, Hermitte menciona que «al poseer un número mayoritario de naguales, hace de ella una persona importante, con mayor sabiduría, y por lo tanto mayor poder sobre los otros. Así, por ejemplo se pueden distinguir a los me'iltatil del hombre común por su buen ch'ulel y por sus trece naguales. Tanto su excelente ch'ulel como sus numerosos naguales le dan sabiduría, poder e inmunidad» (Hermitte op. cit., p. 96). Asimismo, Pitarch plantea que la posesión de trece lab en una persona es una característica que hace de ella un «ser humano completo» (Pitarch op. cit., p. 72).

De igual forma, Jaime Page explica esta importancia: «Este número tiende a variar, ya que puede ser de tres a trece y que dependiendo del número que se tenga podrá sobrevivir ante los percances de la vida (Page op. cit., p 182). Entonces, la persona que posea trece ch'ulel y trece vayijel son personas poderosas, en conocimiento, en control sobre los demás, definiéndose como «persona completas».

La idea del tipo de animal compañero que posea una persona depende del estado físico e intelectual. A esto, Favre comenta que «el poder del animal compañero, de igual forma va a depender del poder que posee la persona» (Favre op. cit., p. 259). Recordando también la importancia de la cantidad de éstos en la persona, define así el «poder» que tenga ante los demás. Al explicar la jerarquía de poder, Pitarch supone que entre las personas de Cancuc «depende a partir del número de lab que posea cada uno. Pero al mismo tiempo, los lab de una persona pueden ser diferentes» (Pitarch op. cit., pp. 69$70)$.

\section{MONTAÑAS CH'IEBAL}

Dentro de la cosmovisión tsotisl-tseltal se encuentran las montañas sagradas ch'iebal, la raíz de esta la palabra «proviene de la palabra " $C h$ ' $i$ ” que significa "crecer". La atención de los niños-ch'ulel parece ser colectiva, responsabilidad de la fratría en su conjunto» (Pitarch op. cit., p. 40). Este representa la descendencia patrilineal y, al mismo tiempo, es una representación geográfica en la que identifica a cierta sociedad. Es el lugar donde habitan los vayijelal de los habitantes de cada grupo patrilineal (Holland op. cit., p. 105; Favre op. cit., p. 260). 
Estas montañas sagradas son igualmente parte del Mundo ch'ulel, ya que físicamente sí se pueden percibir, pero representan más a lo intangible, pues en ellas se encuentran los ch'ulel. Por su descripción cabe mencionar que estas montañas no solo delimitan los municipios a partir de patrias, sino también es toda una comunidad de deidades, de seres sobrenaturales, de ancestros padres-madres, de ch'uleltik en general.

Page describe estas montañas como un «lugar donde Dios acorraló a los vayijeltik para que no hicieran daño - motivados por el diablo - a las personas, cuidados por los Anjeletic denominados "vaqueros", quienes se asisten con unos perros finos que Dios les mandó» (Page op. cit., p. 191). Por su parte, los zinacantecos las nombran en lengua tsotsil «B'ankilal Muk'ta Vits» (Vogt 1966: 115), donde se hallan los chanuletik - plural de chanul - de cada uno de los habitantes de este municipio.

\section{SK'IN CH'ULELAL, DÍA DE MUERTOS}

La fiesta de día de muertos es un ritual complejo en el que no solo participan las personas, ya sea directa - estando presente en los rituales - o indirectamente - mandando la parte que les corresponda, ya sea en especie o en dinero-, sino dentro de estos rituales también participan los ch'ulel de las personas, junto con los ch 'ulelal $^{3}$ de los ya fallecidos. En este ritual se presenta una estructura compleja tanto jerárquica, de parentesco, como religiosa; pues en ella se manifiestan órdenes familiares en las que el ch'ulel de los vivos «convive» con los ch'ulelaletik de los ya muertos. Esta práctica forma parte también del Mundo ch'ulel, ya que en ella se manifiestan las dos partes: tangible e intangible, en el ch'ulel de las personas presentes, como los ch'ulelaletik de los ya no vivos.

Para comprender un poco acerca de este término ch'ulelal, el estudio realizado en Oxchuk por Alfredo Gómez (2007: 18-19) define ch'ulelal como una percepción con la que los oxchuqueros designan las apariciones del ch'ulel de personas muertas; también da la diferencia entre ch'ulel y ch'ulelal. Menciona que ch'ulelal se presenta en los dos espacios, en lo terrenal y en el «otro balmilal» — cielo-inframundo—. En cambio, el ch'ulel solo se sitúa en el «otro balmilal». 
Para diversos estudios realizados con respecto al ch'ulel dentro de la cosmovisión tsotsil y tseltal, el día de muertos es una de sus características. Esta celebración refleja el agradecimiento a la herencia de la tierra, ofreciendo comidas y bebidas, dándoles al mismo tiempo el derecho a la propiedad, constituyendo asimismo una obligación (Guiteras op. cit., p. 127; Gossen op. cit., p. 62; Collier op. cit., p. 205; Pitarch op. cit., p. 53; Page op. cit., p. 177; Pozas 1977: 185).

La explicación que proporciona Manuel Arias sobre este ritual es el agradecimiento por haber dejado la tierra para vivir y al mismo tiempo pedirles que intercedan ante los dioses por ellos.

\footnotetext{
Es el día en que los vivos hacen comunión con los muertos, se les pide que los perdonen y promete esforzarse más al año siguiente y les suplican que no los olviden. Quienes saben rezar dicen diez Padrenuestros por un hombre y diez Avemarías por una mujer. Ruegan a sus difuntos que intercedan ante los dioses que les den otro año de vida para poderles ofrecer, nuevamente, comida y bebida. De este modo, resulta en interés de los muertos conservar la existencia de los vivos (en Guiteras op. cit., pp. 127-128).
}

En estas afirmaciones nos podemos dar cuenta de la mezcla entre la cosmovisión maya y la religión cristiana, en la que se distinguen las oraciones como el Padrenuestro y el Avemaría, hacia las deidades que no precisamente son un Dios católico y una Virgen María. Con ello también nos hacen saber que los muertos, más bien los ch'ulelal, funcionan como intermediarios entre los dioses y las personas.

Al respecto, Jane Collier menciona que «es una obligación dar las ofrendas en este día para tener derecho a la propiedad, de lo contrario acarreará conflictos. Estas costumbres corroboran el derecho de un heredero a la propiedad paterna (Collier op. cit., p. 205). Entonces, la autora deduce que esta fiesta es como una obligación que se da más que nada para evitar conflictos con respecto a la propiedad de terrenos. Mas no le da mucha insistencia al agradecimiento del ch'ulel del que hereda. 
Dentro del destino del ch'ulel, Page explica acerca de su regreso una vez cada año, en Todos Santos — menciona - «Vienen a visitar a sus familiares quienes les obsequian los alimentos y bebidas que fueron de su agrado; los niños el día primero, y los adultos el dos de noviembre. Se supone que tan sólo regresan los ch'uleltic hasta el punto en el que conservan cierta memoria de su vida anterior, es decir, antes de que se rompa el nexo con la persona que antes fue (Page op. cit., p. 177). Un dato importante que nos menciona el autor es la memoria que tiene el ch'ulel de la persona a la que pertenece o perteneció, esto va a depender del número de años que vivió aquí en la tierra.

Por su parte Pitarch, quien no hace mucho énfasis en cuanto a esta fiesta, menciona solamente cuando trata sobre la muerte y el ch'ulel ya en el k'atinbak. «De los muertos, me explican, no cabe esperar ningún daño y se les ofrenda "por afecto", para agradecer a los padres y a los abuelos que cedieran la tierra y porque así se reúnen los miembros de un jun kuil mamil y deciden la tierra que va a ser cultivada por cada grupo doméstico la temporada siguiente» (Pitarch op. cit., p. 53). Aquí es importante rescatar la aclaración que se da en cuanto a la llegada de los ch'ulelaletik, de los muertos, lo de «no temerles», pues ellos vienen a convivir con sus familiares; sabiendo que en países norteamericanos, una característica de la fiesta relacionada con el día de muertos, el «Halloween», es la de horrorizar, asustar, a la gente con los disfraces utilizados en estos días, representando a la muerte de una manera muy distinta a la celebración que se hace en la cosmovisión maya.

\section{CONCLUSIONES}

En este artículo he presentado un breve recuento de la abundante y compleja literatura acerca del concepto ch'ulel, junto con los demás conceptos que se interrelacionan con éste. A lo largo del escrito lo he podido sintetizar en un «estado de la cuestión», aportando al debate teórico estos elementos, nociones y rituales relacionados entre sí. Asimismo, dejar claro que este concepto es más que un simple término denominado «alma», pues conlleva mucho más, interrelacionándose con otros elementos que también son parte de la persona tsotsil-tseltal, y esta a su vez con la sociedad. 
Es, pues, una preocupación más por la recuperación de conceptos que por años han sido traducidos de una manera homogénea y sencilla para explicar cómo es el término «alma», que quizá su significado en la concepción cristiana sea trascendente, pero para comprender la cosmovisión maya no resulta tan eficiente.

Los textos aquí presentados no abarcan obviamente toda la literatura concerniente al tema del ch'ulel, pues queda mucho por buscar y revisar, por hacer y escribir; ya que, como escritora de origen tsotsil considero importante y trascendente las últimas aportaciones que se han realizado por los mismos tsotsiles y tseltales de la región de Los Altos de Chiapas, desde su propia perspectiva, en una mirada desde «adentro», valorando nuestros elementos cosmogónicos que durante décadas han sido estudiados por los de «afuera» de nuestra cosmovisión, que sin duda alguna han dado un gran aliento - y lo siguen dando- a toda esta nueva generación de escritores tsotsiles y tseltales, algunos presentados ya en este artículo.

Estos escritores son, entonces, una muestra de preocupación por los originarios de estas tierras, dándole un valor a la voz propia de la persona tsotsil y tseltal. Queda mucho por investigar, no obstante es importante reconocer que hay investigadores tsotsiles y tseltales que día con día están preocupados por investigar y adquirir el conocimiento de su propio entorno cosmogónico y social.

Por ello, elementos como el ch'ulel y otras nociones tan complejas de conceptualizar, considero que se deben continuar estudiando y revisando, ya sea desde distintas y/o nuevas miradas, como la antropológica, sicológica o lingüística, entre otras, para penetrar al Mundo ch'ulel, y en consecuencia tener y dar cuenta de la comprensión sacralizada del mundo de los pueblos originarios. 


\section{BIBLIOGRAFÍA}

Arias Pérez, Jacinto, 1975, El mundo Numinoso de los mayas: estructura y cambios contemporáneos, SEP, México.

Ch'umil, Saq, Carlos Alvarado, Blanca Estela, Jacinto Coz, 2003, Usaqil K'olem. Tiempo y ser humano en la cosmovisión maya, Maya Diversa, Guatemala.

Collier, Jane, 1995, El derecho zinacanteco: procesos de disputar en un pueblo indígena de Chipas, CIESAS/UNICACH, México.

De La Garza, Mercedes, 1990, Sueño y alucinación en el mundo nahuatl y maya, Instituto de Investigaciones Filológicas, UNAM, México, D. F.

De León Pasquel, Lourdes, 2005, La llegada del alma. Lenguaje, infancia y socialización entre los mayas de Zinacantán, CIESAS, INAH, México.

Favre, Henri, 1992, Cambio y continuidad, entre los mayas de México: contribución al estudio de la situación colonialista en América Latina, 2a. ed., INI-CNCA, México.

Figuerola Pujol, Helios, 1996, «Sujtesel: una oración para buscar el ch’uhlel de una persona en la comunidad tzeltal de San Juan Cancuc, en las altas tierras de Chiapas, México», Amerindia, n. 21.

Gómez López, José Alfredo, 2007, «Yomel. Ceremonia para la unión del alma con el cuerpo en Oxchuk, Chiapas», Tesis de licenciatura, Universidad Autónoma de Chiapas, San Cristóbal de Las Casas, Chiapas.

Gómez Sántiz, María Magdalena, 2005, J’iloletik. Médicos tradicionalistas de los Altos de Chiapas, CELALI-CONECULTA, Tuxtla Gutiérrez, Chiapas.

Gossen, Gary H., 1980, Los chamulas en el mundo del sol: tiempo y espacio en una tradición oral maya, INI, México. 
Guiteras Holmes, Calixta, 1961, Los peligros del alma, visión del mundo de un tsotsil, Fondo de Cultura Económica, México.

Hernández Díaz, Miguel, 1997, Ideas y creencias en San Andrés Larráinzar, CELALI, San Cristóbal de Las Casas, Chiapas.

Holland, William Roland, 1963, Medicina maya en los Altos de Chiapas, Instituto Nacional Indigenista, México.

Hermitte, Esther, 1970, Control social y poder sobrenatural en un pueblo maya contemporáneo, Instituto Indigenista Interamericano, México.

Köhler, Ulrich, 1995, Chonbilal Ch'ulelal-Alma Vendida. Elementos fundamentales de la cosmología y religión mesoamericana en una oración en maya-tzotzil, Universidad Nacional Autónoma de México, México, D.F.

Page Pliego, Jaime Tomás, 2005, El mandato de los dioses. Etnomedicina entre los tzotziles de Chamula y Chenalhó, Chiapas, PROIMMSE-IIA-UNAM, México.

Pérez López, Enrique, 1997, Slumal jachom'etik. Chamula: Un pueblo tzotzil, CONECULTA-CELALI, México.

Pozas Arciniega, Ricardo, 1977, Chamula: Un pueblo indio de los altos de Chiapas, Memorias del Instituto Nacional Indigenista, México.

Pitarch, Pedro Ramón, 1996, Ch’ulel: una etnografía de las almas tzeltales, Fondo de Cultura Económica, México.

Ruz, Mario Humberto, 1992, «Los mayas de hoy: pueblos en lucha», en Del katún al siglo. Tiempos del colonialismo y resistencia entre los mayas, María del Carmen León, Mario Humberto Ruz, José Alejos García, CONACULTA, México, pp. 191-267. 
Sánchez Álvarez, Miguel, 2006, «Lenguas maternas y los recursos naturales», en Jabil ame IV, CELALI, Tuxtla Gutiérrez, Chiapas, pp. 55-65.

Vogt, Evon Z., 1966, Los zinacantecos, Presencias, México, D. F.

1992 «Cruces indias y bastones de mando en Mesoamérica», en De palabra y obra en el nиеvo mundo. 2 Encuentros interétnicos, editado por Manuel Gutiérrez Estévez, Miguel León-Portilla, Gary H. Gossen, J. Jorge Klor de Alva, Siglo Veintiuno editores, México, pp. 249-294. 


\section{Notas}

\footnotetext{
${ }^{1}$ Cabe mencionar que el término «brujería» no es un concepto maya, sino que es un concepto europeo escrito por autores para explicar las enfermedades provocadas por terceras personas.

${ }^{2} \mathrm{El}$ ch'ulel de una persona ya fallecida se denomina ch'ulelal, por lo que ch'ulelaletik es la pluralización de este término.

${ }^{3}$ Se dice ch'ulelal y no ch'ulel, cuando la persona ya se encuentra fallecida.
}

Fecha de recepción: 10 de diciembre de 2009.

Fecha de aceptación: 17 de junio de 2010. 